\title{
Las dos torres de Babel en el pensamiento de Michael Oakeshott
}

\author{
JUAN ANTONIO GONZÁLEZ DE REQUENA FARRÉ* \\ Universidad Austral de Chile (Chile) \\ jgonzalez@spm.uach.cl
}

\begin{abstract}
Resumen
En el pensamiento contemporáneo, el relato de Babel ha suscitado alegatos teológicos contra los proyectos titánicos del racionalismo moderno y exégesis poéticas en defensa de la diseminación idiomática. Los dos ensayos de Michael Oakeshott titulados "La Torre de Babel" permiten reconocer las principales inquietudes intelectuales del autor y los diferentes dilemas teóricos en la comprensión del Estado europeo moderno. No solo escenifican el aspecto ruinoso del racionalismo moral y el utopismo político, sino también los riesgos de la política de la fe, del colectivismo, y de la reducción de las asociaciones humanas a transacciones instrumentales o corporaciones empresariales. En la exégesis de Oakeshott, Babel se perfila como un mito político moderno, que exhibe una marcada ambivalencia mediante la convergencia de motivos éticos, religiosos, políticos e, incluso, poéticos.
\end{abstract}

Palabras clave: racionalismo; colectivismo; utopismo; civilidad; mito.

\section{The two towers of Babel in the thought of Michael Oakeshott}

\begin{abstract}
In contemporary thought, the story of Babel has raised theological arguments against the titanic projects of modern rationalism and poetic exegesis in defense of idiomatic dissemination. The two essays by Michael Oakeshott entitled "The Tower of Babel" allow to recognize the main intellectual concerns of the author and the different theoretical dilemmas in the understanding of the modern European State. They not only illustrate the ruinous aspect of moral rationalism and political utopianism, but also the risks of the politics of faith, of collectivism, and of the reduction of human associations to instrumental transactions or enterprise corporations. In the exegesis of Oakeshott, Babel emerges as a modern political myth, showing a marked ambivalence through the convergence of ethical, religious, political, and even poetic motives.
\end{abstract}

Key words: rationalism; collectivism; utopianism; civility; myth.

\footnotetext{
* $\quad$ Doctor en Filosofía (Universidad Complutense de Madrid). Profesor asociado del Instituto de Psicología de la UACh, Sede Puerto Montt. Artículos recientemente publicados: "De vuelta en la caverna platónica con Michael Oakeshott" (2017); "Los derechos fundamentales epistémicos y comunicativos en la era de la posverdad" (2018); "La conceptualización de la mentira en tiempos de la posverdad" (2019).

Artículo vinculado al proyecto Fondecyt Regular no 1190030, investigación financiada por CONICYT.
} 
En el curso del siglo XX, la alegoría de la Torre de Babel ha generado básicamente dos tipos de interpretaciones: en cierta exégesis filosófico-religiosa, se ha tematizado sobre todo la empresa de construcción de la torre, como emblema de los excesos del racionalismo moderno y de la fragilidad de los sistemas ideológicos; en la interpretación filosóficolingüística, el foco central ha sido la dispersión idiomática y la confusión de las lenguas, como pretexto para afirmar el carácter creativo e inevitable de la traducción. Ahora bien, en el pensamiento contemporáneo hay un autor que recurrió en distintas ocasiones a la alegoría de la Torre de Babel, y que, en sus interpretaciones del mito, expresó ambas inquietudes, esto es, la crítica del racionalismo y la invitación a la conversación entre las distintas voces de la humanidad. Se trata de Michael Oakeshott. Este pensador británico dio a dos de sus ensayos el título "La Torre de Babel": el primero, publicado en 1948 e incluido en El racionalismo en la política y otros ensayos (2000), plantea una crítica del racionalismo en moral; el segundo aparece como capítulo final del libro Sobre la historia y otros ensayos (originalmente publicado en 1983, aunque su origen se remonta a una conferencia impartida en 1979), y asume una forma más narrativa para cuestionar el pensamiento propositivo, el colectivismo productivista y la mentalidad adquisitiva.

En este artículo, pretendemos reconstruir los usos de la Torre de Babel en la obra de Oakeshott, por medio de una interpretación contextual de la función de esa alegoría en cada etapa del pensamiento del pensador británico. $\mathrm{Y}$ es que la exégesis de las versiones de esta recurrente alegoría en el pensamiento de Oakeshott podría contribuir significativamente al estado de la investigación sobre el pensador británico: (a) al poner de manifiesto cómo en la obra de Oakeshott se entrelazan las principales inquietudes y líneas interpretativas (filosófico-religiosa y filosófico-lingüística) del relato de la Torre de Babel; (b) al clarificar, a través de las dos versiones de la alegoría en Oakeshott, las principales encrucijadas intelectuales planteadas por el pensador británico; (c) al sistematizar las interpretaciones de la alegoría entre los especialistas en Oakeshott; (d) finalmente, al rescatar el trasfondo mitopoético de la escritura filosófica del pensador británico, así como cierto mito político subyacente a su teorización política. En la siguiente sección, sintetizaremos el estado de la discusión sobre la Torre de Babel en la cultura contemporánea, para así justificar la ambivalente integración de las tradiciones interpretativas en las dos versiones de la alegoría de Oakeshott. La sección central da cuenta del desarrollo del pensamiento de Oakeshott a partir de los estratos de significado contenidos en los dos textos titulados "La Torre de Babel". 
Finalmente, en la conclusión sistematizamos las principales claves interpretativas de ambos ensayos de Oakeshott, discutimos las exégesis propuestas por los especialistas en el autor y exploramos el decisivo trasfondo mitopoético que la Torre de Babel esboza en el pensador británico.

\section{El BABEL CONTEMPORÁNEO}

La imagen de la Torre de Babel —esa portentosa construcción encumbrándose hasta lo más alto del paraje de la ciudad terrenal, atravesada por la dispersión y fragmentación de las lenguas- se ha transformado en un emblema de nuestra propia época. Bajo la forma de alegoría monumental y arquitectónica, la Torre de Babel desempeñaba una función simbólica decisiva en la película Metrópolis, dirigida por Fritz Lang en 1927. En Metrópolis, aparece relatada explícitamente la historia legendaria de Babel, y se designa como Nueva Torre de Babel al monumental edificio o torre de control central que albergaba la dirección de un orden titánico, basado en la dominación técnica de las masas y en cierta dispersión de los registros (confusión atribuible a la incomunicación clasista entre la mecánica existencia de los trabajadores alienados y el entretenimiento frívolo de las élites privilegiadas). El diseño de la Torre de Babel en $M e-$ trópolis reproducía la iconografía tradicional de un monumento colosal o de un coliseo proyectado por estratos hacia una altura incalculable. Esta alegoría arquitectónica de la Babel de Metrópolis se ha vuelto tan icónica que la Unesco incluyó a esta película en el Registro de la Memoria del Mundo (el año 2001), por considerarla un testimonio histórico y un modelo simbólico del futuro.

Como contrapartida, algunos críticos culturales han considerado que, aunque recogía simbólicamente algunos de los temas de la crisis sociohistórica contemporánea (como el problema de la técnica y el culto por la máquina, el protagonismo de las masas, la lucha de clases y la rebelión generacional), la película de Lang constituía un síntoma decadente de la confusión reinante en los años veinte en la República de Weimar. En lugar de explorar la crítica de la realidad política, la extravagancia alegórica de Metrópolis subordinaba el lenguaje cinematográfico a la exhibición técnica, el montaje artificial y la ornamentación pomposa; asimismo, terminaba identificando la revuelta social con una demoniaca y fríamente calculada manipulación, y se conformaba con apelar a una falsa reconciliación de clases sustentada en una sospechosa mediación cordial (Gay, 1984: 156; Kracauer, 1985: 142-143).

Además de reproducirse en la industria cinematográfica y la cultura popular, la alegoría de Babel ha tenido una significativa recepción en el pensamiento cristiano del siglo XX. Ya en la década de los treinta, Rein- 
hold Niebuhr, influyente pastor evangélico y teólogo político norteamericano, interpretaba dialécticamente el sentido del relato bíblico en su ensayo "The Tower of Babel", incluido en el libro Beyond Tragedy (publicado en 1937). En su sermón ensayístico, Niebuhr considera que la leyenda de Babel puede haberse originado contingentemente como un intento de explicar la majestuosidad en ruinas de los templos babilónicos o la diversidad idiomática, pero nos deja un mensaje permanente que entronca con el mito prometeico sobre la ambición humana y el celo divino, o bien con la narrativa moderna sobre la inevitable finitud de las empresas culturales y civilizatorias de la humanidad. Para Niebuhr, la humanidad construye sus torres cada vez que intenta trascender su finitud e ir más allá de nuestro alcance; pero, cuanto más pretencioso sea el intento de superar nuestras limitaciones, más inevitablemente se exponen nuestras construcciones culturales y civilizatorias a su propia autodestrucción trágica. En cada caso, los proyectos culturales de la humanidad esbozan nuevas torres de Babel, cada vez más pretenciosas, sobre las ruinas de las anteriores. Pero en el mismo momento en que se concibe ilusoriamente la perfección eterna de algún orden cultural, se manifiestan dialécticamente las fisuras a través de las cuales se arruinará la arrogancia humana, como si las expectativas de inmortalidad por las realizaciones humanas tuviesen como reverso un ruinoso destino mortal (Niebuhr, 1937: 30-41).

No es de extrañar que - desde la perspectiva teológico-política de Niebuhr- el castigo divino por la arrogancia humana consista en remarcar la finitud espiritual de la humanidad, tal como se evidencia en la insuperable diferencia de las lenguas y la dispersión de las culturas. En ese sentido, la interpretación de Niebuhr asocia la significación de la Torre de Babel a los excesos de un racionalismo moderno que intenta sobrepasar sus limitaciones, la finitud y contingencia de cualquier proyecto espiritual humano, al idealizar cierto lenguaje y cultura universales (Niebuhr, 1937: 44).

También el filósofo católico Dietrich von Hildebrand recogió la alegoría bíblica en su libro The New Tower of Babel (originalmente publicado en 1953). Bajo la convicción de que la tarea del creyente no consiste en asistir como espectador pasivo al curso de la providencia, Hildebrand hacía de la Torre de Babel un símbolo de los despropósitos humanos y de los peligros espirituales que era preciso desenmascarar y combatir activamente (1994: 3-4). En un escenario de acoso anticristiano a la espiritualidad y forma de vida del cristianismo, puede reconocerse cómo la humanidad moderna ha erigido nuevas torres de Babel, en la medida en que se da un intento de desentenderse de la condición de criatura, de nuestra realidad metafísica y de la trascendencia espiritual. Por ejemplo, 
el existencialismo sartreano, al consagrar la voluntad arbitraria y la autocreación sin limitaciones, esboza una nueva Torre de Babel al desconocer arrogantemente que el ser humano es criatura dependiente y al promover una autosuficiencia individualista sin sentido de la trascendencia, del respeto o de la gratitud (Hildebrand, 1994: 9-11). El intento de renegar de la dependencia humana de Dios se asocia sintomáticamente a una paradójica relación con el conocimiento: cierto relativismo filosófico cuestiona la verdad objetiva absoluta, al tiempo que consagra la ciencia como autoridad última e indiscutible; determinado reemplazo pragmatista del concepto de verdad por la funcionalidad práctica tiene como reverso la aceptación ingenua de la utilidad como significado de la verdad. La nueva Torre de Babel moderna se forja, pues, sobre la autocontradicción insalvable en que incurre quien se aparta de la verdad divina y del conocimiento, para entregarse a la opinión ilusoria y la superstición acrítica (Hildebrand, 1994: 14-15 y 65-82).

En fin, las recepciones religiosas de la alegoría de la Torre de Babel no parecen limitarse a reproducir sintomáticamente la vanidad colosal, ya que adoptan un tenor crítico y un tono de denuncia ejemplar ante los excesos de la idolatría y las ilusiones desmedidas. No obstante, como bien entrevió Niebuhr, también la idealización cristiana de la comunidad de fe y la verdad absoluta puede esbozar la desmesura de una nueva Torre de Babel que no asume la fragmentación y finitud de la condición humana. En ese sentido, tal vez la alegoría cristiana de la Torre de Babel solo puede interpretarse en el umbral indecidible entre el mito salvífico y tragedia humana.

Ya en la segunda mitad del siglo XX, la recepción de la alegoría de la Torre de Babel ha remarcado primordialmente cuanto concierne a la multiplicación de las lenguas y los problemas de traducción, en lugar de expresar la condena teológica de los excesos del racionalismo moderno, como la encontramos en Niebuhr o Hildebrand. En su monumental ensayo Después de Babel (originalmente publicado en 1975), George Steiner da curso a una sofisticada reflexión sobre los múltiples matices con que, en las tradiciones religiosas, filosóficas y literarias, así como en la ciencia lingüística y en el oficio de la traducción, se ha problematizado la diversidad de las lenguas y los problemas de la traducción. Al asumir que la diversidad de las lenguas es un rasgo de la individuación humana, y al sostener que la tarea poética de la traducción resulta central tanto para cualquier modalidad de comunicación lingüística como para entender el lenguaje como un todo, Steiner interpreta el significado de Babel de manera peculiar. En primera instancia, Babel parece proseguir una inevitable opción por la traducción una vez que la humanidad apostó por articular un lenguaje común para una comunicación eficaz, o bien consagró el 
ideal de una voz poética expresiva capaz de transparentar la imagen del mundo, con exclusión de otras posibilidades semióticas; de ese modo, "Babel confirmó y ensanchó la tarea interminable del traductor —no la inició" (Steiner, 1980: 68).

Para Steiner, la imagen emblemática de la Torre de Babel ha suscitado todo tipo de mitologías y especulaciones filosóficas que revelan algunos aspectos de la fragmentación de la palabra humana. En algunos casos, los relatos culturales enfatizan el carácter accidental de la dispersión lingüística, y, en otros casos, se alude a un castigo divino por la arrogancia humana, que concluyó con el aislamiento de las lenguas y el olvido de la palabra universal. Toda una teología del lenguaje concibe, así, Babel como una segunda caída que nos habría despojado de la comprensión plena y de la certidumbre de comunicar la realidad; incluso, en algunas lecturas místicas, se especula la posibilidad de pasar de Babel a algún momento mesiánico de inteligibilidad plena y armónica. Las tradiciones gnósticas y ocultistas soñarían a su manera con la restitución de una gramática universal y la manifestación de una verdad plena mediante alguna lengua perfecta, ya se trate de un idioma vernáculo privilegiado, alguna clave secreta, alguna lengua subyacente o un silencio revelador, más allá del clamor de las lenguas dispersas (Steiner, 1980: 77-84).

Según Steiner, también las teorías del lenguaje se han enfrentado al problema de la posibilidad de la traducción tras Babel, desde perspectivas contrapuestas, que a veces insistían en la universalidad de las estructuras subyacentes del lenguaje (con el riesgo de consagrar una concepción abstracta y formalista de las relaciones entre lenguaje, mente, sociedad y cultura), o bien remarcaban la singularidad expresiva de cada lengua, de modo que la traducción sería tan difícil como inevitable. Frente a las especulaciones gnósticas y las teorías filosóficas o lingüísticas que idealizan la reposición de alguna lengua primordial o gramática universal, Steiner explora otras interpretaciones de Babel que enfatizan la polisemia y opacidad de la palabra humana, la condición políglota de la humanidad y el imperativo de la traducción. Para Steiner, el mito de Babel encierra cierta inversión simbólica, pues la dispersión de las lenguas no arruinó a la humanidad, sino que garantizó su capacidad creadora. En una de las interpretaciones de Babel, Steiner especula poéticamente sobre la opacidad, pluralidad y singularidad irreducible de las lenguas, cuyo reverso es el silencio monótono o la expresión muda:

Es concebible que hayamos interpretado erróneamente el mito de Babel. La construcción de la torre no coincidió con la desaparición de un monismo privilegiado, de un estado de universalidad lingüístico. La desquiciante profusión de las lenguas existió desde siempre, complicando materialmente 
la ejecución de las empresas humanas. Pero cuando intentaron levantar la torre, las naciones del mundo tropezaron con el gran secreto: la comprensión verdadera solo se daba en el silencio. Se pusieron a construir sin decir palabra: ese era el peligro para Dios. (Steiner, 1980: 327)

$\mathrm{Al}$ cierre del ensayo, Steiner recupera una inquietante hipótesis de la Cábala — relativa a nuestra condición postbabélica—, según la cual habrá un momento en que la traducción será imposible, y se impondrá el silencio (Steiner, 1980: 548).

Como Steiner, Jacques Derrida vinculó la alegoría de la Torre de Babel a los problemas e inevitabilidad de la traducción, en un conocido texto de 1985, cuyo título ilustra la dificultad de traducir: Des Tours de Babel; es decir, Torres de Babel, pero también, retornos de Babel o desvios de Babel. En el texto de Derrida, el mito de la Torre de Babel y el mismo nombre propio de Babel son objeto de una interpretación deconstructiva que remarca la diseminación de los registros, el juego indecidible de los significantes, la necesidad e imposibilidad de la traducción, así como la incompletitud sistemática del lenguaje. En primera instancia, Derrida considera que el relato de la Torre de Babel representa figurativamente tanto la pluralidad de las lenguas como la inevitabilidad de las trasposiciones figurativas y giros translaticios:

Al expresar al menos la inadecuación entre una lengua y otra, entre un lugar de la enciclopedia y otro, entre el lenguaje consigo mismo y con el sentido etc., expresa también la necesidad de la representación, del mito, de los tropos, de los giros, de la traducción inadecuada para suplir lo que la multiplicidad nos niega. En ese sentido sería el mito del origen del mito, la metáfora de la metáfora, el relato del relato, la traducción de la traducción, etc. (Derrida, 1987: 35)

Por otro lado, para Derrida, la alegoría de la Torre de Babel y de la diseminación de las lenguas da cuenta del inacabamiento inherente de cualquier intento de consumar la expresión plena y transparente del sentido en algún sistema arquitectónico o construcción coherente; podría considerarse una figura traslaticia de la interpretación deconstructiva o una "traducción de un sistema de deconstrucción" (Derrida, 1987: 35). La operación deconstructiva a que Derrida somete el relato de la Torre de Babel explota la propia ambivalencia del nombre de Babel: si bien es nombre propio intraducible (en tanto que nombre patronímico de la ciudad de Dios y nombre del padre como origen de las lenguas), también se presenta como el nombre común para designar la confusión. Como significante, Babel es de modo indecidible nombre propio y común, in- 
traducible y translaticio, interno a la lengua y extraño al sistema lingüístico. Por eso, cuando en el relato de Babel Dios impone su indecidible nombre de padre, da curso también a la deconstrucción de sí mismo y de la lengua universal, y emprende la diseminación de los registros; introduce el juego indecidible que hace fracasar la universalización idiomática, la transparencia racional o la univocidad, e inscribe el imperativo y la deuda de una traducción tan necesaria como inviable. Para Derrida, la deuda de la traducción impuesta con Babel no resulta cancelable y esa es la clave de la "performance babélica" (Derrida, 1987: 42).

¿Cómo se posicionan en este ambivalente panorama babélico del pensamiento contemporáneo las dos torres de Babel de Oakeshott?

\section{LA DOBLE PRESENCIA DE LA ALEGORÍA DE BABEL EN OAKESHOTT}

Un hilo conductor reconocible a través de los escritos filosóficos de Oakeshott consiste en la afirmación de la pluralidad de la experiencia, en la diversidad y autonomía de las diferentes perspectivas abstractas del mundo, o bien en la diferencia de las voces y lenguajes de la imaginación que concurren en la conversación humana (Podoksik, 2003: 36). Así pues, no es de extrañar que la alegoría de Babel - la cual da cuenta de la dispersión de los registros idiomáticos y las experiencias culturales- haya desempeñado una función relevante en distintos momentos de la producción teórica del pensador británico.

Sin embargo, no existen referencias al escenario alegórico de Babel y a nuestra condición postbabélica en la obra de Oakeshott que precisamente introduce la visión pluralista según la cual existen diferentes perspectivas de la realidad, es decir, mundos de ideas abstractos y homogéneos dentro de sus confines (como la ciencia, la historia o la práctica). En Experience and its Modes (originalmente publicado en 1933), Oakeshott defiende el planteamiento de que la experiencia humana constituye una totalidad diferenciada o una unidad diversa, cada uno de cuyos enfoques, versiones o modos representa un tipo de ideación lograda y relativamente coherente, aunque cada mundo de ideas resulte fallido y contradictorio como modalidad abstracta, separada y acotada de la experiencia. Y es que la experiencia humana solo se concibe cabalmente y sin limitaciones - esto es, filosóficamente- desde la perspectiva de la totalidad concreta (Oakeshott, 1966: 322-330). En el planteamiento de Experience and its Modes, se reconoce el influjo del idealismo británico, a través de la afirmación del carácter constitutivo de las ideas en la conformación de los diferentes mundos de experiencia y modos de comprensión. Pero, a diferencia de los neohegelianos, Oakeshott considera que los mundos de experiencia no se disponen jerárquicamente, ya que son creaciones con- 
tingentes con criterios específicos de verdad y realidad, aunque algunas formas de experiencia solo reúnan incoherentemente ideas de distintos modos y sean fuente de error y confusión (Nardin, 2001: 2).

Curiosamente, tampoco se menciona la condición postbabélica en Experience and its Modes, a pesar de que el libro versa en gran medida sobre la confusión, esto es, la interferencia y la irrelevancia a que se ve expuesta la experiencia humana cuando no conseguimos determinar el significado de cada mundo de ideas distinto y transitamos acríticamente de un modo de experiencia a otro (Oakeshott, 1966: 5). En efecto, gran parte de Experience and its Modes está dedicada a establecer distinciones modales y criticar las diversas formas de error categorial y confusión intelectual en que se incurre cuando la vida práctica padece las intrusiones irrelevantes de la ciencia o la historia, o bien cuando la historia sufre las intromisiones irrelevantes de la ciencia y la actitud práctica (Franco, 2004: 39).

\subsection{La primera torre de Babel (1948)}

Tras la Segunda Guerra Mundial, Oakeshott parece distanciarse del idealismo de Experience and its Modes, es decir, de la consideración de los modos de experiencia como abstracciones de la totalidad de la experiencia concreta, de manera que solo la perspectiva concreta de la filosofía podría concebir un mundo coherente de experiencia más allá de las limitaciones abstractas de la historia, la ciencia y la práctica. En los textos de los años cuarenta y cincuenta recogidos en El racionalismo en la política y otros ensayos, Oakeshott abandonó aparentemente el monismo idealista, y asumió una nueva comprensión pluralista de las actividades, modos de imaginación y voces idiomáticas involucradas en la conversación humana (Franco, 2004: 125-126). En este nuevo marco de comprensión de la experiencia humana como ámbito de encuentro conversacional de las distintas voces, sin que exista un árbitro de la coherencia de las versiones o una perspectiva ideal privilegiada, Oakeshott recoge la alegoría de la Torre de Babel.

En el ensayo "La torre de Babel" incluido en El racionalismo en la politica y otros ensayos, Oakeshott emplea la alegoría babélica para ilustrar los riesgos de cualquier proyecto titánico o empresa desmedida, que ambicionen conquistar colectivamente la perfección ideal. En ese sentido, el propósito de la perfección constituye un aspecto de la actividad humana tan impío como inevitable. Ahora bien, el perfeccionismo moral no es fatal para el individuo, pues la recompensa de la búsqueda heroica puede compensar el precio de la derrota final; pero la proyección colectiva de 
ideales perfeccionistas solo puede conducir a la cháchara confusa de los ideales contrapuestos y a la rigidez ideológica:

[...] para una sociedad, el castigo es un caos de ideales en conflicto, la perturbación de una vida en común, y la recompensa es el renombre que corresponde a una locura monumental. A mesure que l'humanité se perfectionne l'homme se dégrade. (Oakeshott, 2000: 427-428)

Así pues, este primer ensayo sobre la Torre de Babel introduce la alegoría para discutir las consecuencias del racionalismo moral, tal como se manifiesta en aquella comprensión de la vida moral que reduce nuestra actividad a la aplicación reflexiva de criterios morales, la búsqueda consciente y deliberada de ideales perfeccionistas, o bien la observancia y aplicación reflexiva de reglas abstractas de comportamiento. Para Oakeshott, una forma de vida moral sustentada en la búsqueda reflexiva de la perfección ideal solo generará incertidumbre sobre las actuaciones concretas, un debilitamiento de la sensibilidad moral habitual, modalidades de conducción moral inflexibles y liderazgos rígidos, desencanto por las expectativas ideales incumplidas y dilemas entre ideales extremos abstractos (Oakeshott, 2000: 435-437). A esta forma contraproducente de racionalismo perfeccionista, se contrapone la comprensión de la vida moral como hábito de comportamiento y costumbre flexible, seguimiento irreflexivo y familiar de nuestras tradiciones consuetudinarias, o bien adquisición tácita de hábitos afectivos matizados a través de la educación moral cotidiana (Oakeshott, 2000: 429-433). En todo caso, estas formas de comprender la vida moral constituyen solo tipos ideales que no se pueden oponer como extremos, pues habitualmente nuestra vida moral integra hábito y reflexión. Pero, si predomina el extremo racionalista, como parece haber ocurrido en la tradición de la Ilustración moral y las búsquedas ideológicas de una moralidad científica, corremos el riesgo de olvidar el carácter poético de la actividad humana - esa capacidad expresiva, apasionada y creativa para forjar lenguajes sutiles de actividad-, que no se deja reducir a ideales morales reflexivos, meras abreviaturas abstractas de nuestros hábitos de comportamiento. Para Oakeshott, el efecto de la Torre de Babel en la moralidad europea moderna parece haber sido la desintegración del hábito de comportamiento flexible y su reemplazo por la búsqueda de coherencia en alguna ideología utópica, abstracta y pretendidamente universal (Oakeshott, 2000: 438-439).

Ciertamente, la crítica del racionalismo perfeccionista apuntada en la interpretación de "La Torre de Babel" de 1948 concuerda con el propósito del ensayo "El racionalismo en la política" de 1947. Frente a la tradición de racionalismo político que ha convertido en guía incuestionable 
de la actividad humana a la razón, las ideas abstractas, la reflexión consciente, el propósito perfeccionista, la uniformidad ideológica, la soberanía de la técnica y el seguimiento de reglas de aplicación universal, Oakeshott reivindica el conocimiento práctico circunstancial que se expresa en la familiaridad tácita con un hábito afectivo y de comportamiento, así como en las sugerencias irreflexivas y flexibles de la tradición (Oakeshott, 2000: 21-32). Sin embargo, en El racionalismo en la política y otros ensayos hay otra referencia a la alegoría de Babel que se centra en la multiplicidad de las voces idiomáticas y en la pluralidad de los registros de la actividad y la imaginación humanas. El ensayo de 1959 titulado "La voz de la poesía en la conversación de la humanidad" parece asociar el acontecimiento de Babel a la coexistencia de diferentes modos de hablar y distintas voces o expresiones idiomáticas (como la historia, la práctica, la ciencia o la poesía), pese a los intentos filosóficos de concebir un solo modo de expresión humana auténtica o una voz privilegiada. Para Oakeshott:

[...] se resiste a morir la idea de que Babel fue la ocasión de una maldición echada sobre la humanidad de la que es tarea de los filósofos librarnos, y persiste una disposición a imponer un carácter singular al discurso humano significativo. (Oakeshott, 2000: 447)

En "La voz de la poesía en la conversación de la humanidad", Oakeshott retrata la condición postbabélica como un encuentro o ámbito de reunión entre distintas voces de la actividad, la imaginación y la comunicación humana, sin que estas se puedan reducir a un solo registro o jerarquizar con un único criterio. Como en toda conversación, no hay una verdad concluyente ni una conclusión única; puede haber diferencias en la modulación y en la expresión sin que ello implique una contradicción argumentativa insalvable:

Hablando con mayor precisión, la conversación es imposible en ausencia de una diversidad de voces: en ella se encuentran diferentes universos de discurso, se reconocen recíprocamente y disfrutan de una relación oblicua que no requiere que los universos se asimilen entre sí ni espera que eso ocurra. (Oakeshott, 2000: 448)

No obstante, la conversación humana está amenazada por la imposición de las voces o por la superbia de aquella voz que pretende reducir la conversación a la exclusiva expresión de su voz o al monólogo vanidoso (Oakeshott, 2000: 451). 


\subsection{La segunda Torre de Babel (1979)}

El otro ensayo de Oakeshott titulado "La Torre de Babel", incluido en el libro Sobre la historia y otros ensayos, narra distintas versiones del mito (hebrea, musulmana y caldea), que habría tenido variaciones en todo un conjunto de relatos culturales a través de la historia de la civilización, desde la Antigüedad hasta el moderno Fausto. El relato hebreo adopta como motivo inicial el deseo humano ilimitado e insaciable, y tiene como protagonista principal al arrogante Nimrod, cuya ambición colosal lo condujo a intentar sobrepasar su inseguridad mediante la construcción de una torre tan alta que permitiera asaltar los cielos. La empresa de edificación de la Torre convertiría a los seguidores de Nimrod en esclavos de un ideal inalcanzable y un proyecto interminable, solo frustrado cuando Dios decide confundir las lenguas e imposibilitar un proyecto colectivo tan desmedido. En las versiones musulmana o caldea, el despropósito de Nimrod y su proyecto insensato de atacar a Dios concluye con el visionario sepultado bajo los escombros de su torre colosal, o bien liquidado irónicamente en el asalto de los cielos (Oakeshott, 2013a: 160-164). Además, Oakeshott construye una versión actualizada del relato, en que Babel se presenta como una ciudad del deseo incontenible, la búsqueda ilimitada de satisfacciones y el afán de entretenimiento sin constancia, cuyo desenlace habría sido un giro irónico de la codicia infinita (Oakeshott, 2013a: 168). Movida por la ambición infinita y la persecución instrumental de una perfección ilimitada, Babel sucumbirá como consecuencia del trabajo insensato, el inflexible encuadramiento colectivo y la movilización total de los ciudadanos al servicio de la utilidad pública, la falsa ilusión ideológica, la desconfianza y resentimiento ante la postergación de la satisfacción ilimitada y, finalmente, el sepultamiento de la ciudad bajo los escombros de su monumental desmesura:

Aquello que se diseñó como una escalera al paraíso se ha transformado en la tumba de todo un pueblo, que no ha perecido en la confusión de las lenguas sino que ha sido víctima de una falsa ilusión, desconcertado por la desconfianza que siempre acosa a quienes emprenden proyectos titánicos. (Oakeshott, 2013a: 182)

En esta segunda versión de la alegoría de "La Torre de Babel", se pueden reconocer retrospectivamente algunas de las más relevantes inquietudes intelectuales y dilemas teóricos planteados por Oakeshott a través de su obra de Postguerra. En primera instancia, el relato actualizado de la Torre de Babel mantiene la crítica del pensador británico al racionalismo moral, por su propensión a consagrar la planificación perfec- 
cionista, los ideales abstractos y la rígida coherencia ideológica. En la narración alegórica, Oakeshott describe cómo los ciudadanos de la autodestructiva Babel abandonaron su costumbre cotidiana y se sumaron al extravagante proyecto de Nimrod como promotores de una idea suprema y una visión distante:

[...] los babelianos por fin han encontrado un propósito para su vida, para contener sus tendencias díscolas, y se han elevado al estatus de adalides de un ideal. (Oakeshott, 2013a: 171)

Efectivamente, en la nueva alegoría de Babel, Oakeshott introduce muchos de los rasgos con que había caracterizado el carácter racionalista y el racionalismo moral: bajo un ideal deliberadamente construido y perfeccionista, los ciudadanos se conducen como si fuesen incitados por el liderazgo de un experto visionario; siguen la guía severa de la reflexión constante, la investigación metódica y la planificación tecnológica; se obsesionan por las consignas y logotipos ideológicos; pero, de ese modo, se consagran a una ilusión fatal.

Sin embargo, la segunda versión de "La Torre de Babel" también incorpora alegóricamente los dilemas entre otros tipos ideales desarrollados en escritos de los años cincuenta, de manera que, en el proyecto desmesurado y ejecución afanosa de la descomunal torre, se pueden identificar vestigios de cierta política de la fe. En su escrito La política de la fe y la política del escepticismo (redactado a comienzos de los cincuenta y publicado póstumamente en 1996), Oakeshott caracterizaba el tipo ideal de una comprensión de la política que concibe el gobierno como una actividad al servicio de la perfección humana, que controla y organiza los comportamientos humanos, para lograr ese fin perfeccionista y un mejoramiento máximo de la humanidad. Esta política de la fe no solo confía en la capacidad de perfeccionamiento, sino que supone algún acceso privilegiado a una meta utópica o a una condición única y global, y entrega al gobierno todas las competencias para organizar la perfección humana de modo minucioso e inquisitivo (Oakeshott, 1998: 50-57). Como contrapartida de la política de la fe, Oakeshott considera un estilo político marcado por el escepticismo, la desilusión respecto a la perfección humana y las metas utópicas, así como la apuesta desencantada por una actividad de gobernar limitada, que mantenga un orden suficiente o garantice un sistema de derechos y deberes en los asuntos humanos (Oakeshott, 1998: 57-67). Como ocurre con otros de los dilemas entre tipos ideales propuestos por el autor, Oakeshott sostiene que ambos extremos resultan autodestructivos; así pues, se trataría de hallar un estilo complejo 
de hacer política que pueda ubicarse en un punto medio habitable sin inmovilizarse ni colapsar (Oakeshott, 1998: 160-161).

No obstante, algunos especialistas han remarcado cierto idealismo escéptico en el pensamiento de Oakeshott, debido al carácter antifundacionalista y categorialmente acotado de su estilo intelectual y de su crítica del Iluminismo (Tseng, 2003: 4-5). Asimismo, se ha insistido en el escepticismo descreído que caracteriza a la filosofía política de Oakeshott y a su concepción de la actividad civil como una interacción contingente y pluralista, en la cual ninguna voz puede arrogarse la autocerteza plena dentro de la conversación humana, aunque la autoridad reconocida de un sistema formal de leyes suministre un orden superficial para convivir, sin tener que presuponer algún propósito común sustantivo o fin exclusivo de la vida en común (Gerencser, 2000: 1-5). Al margen de ese debate, cuando leemos la descripción de la némesis de la fe en política, se reconocen muchos de los motivos presentes en la alegoría de "La Torre de Babel":

Entonces, la némesis de la fe es el derrumbe inevitable del gobierno cuando se ata a la búsqueda de la "perfección": el empeño de imponer una sola pauta de actividades a la comunidad es contraproducente, y esto se ilustra también en lo que podríamos llamar su lógica de la "seguridad". (Oakeshott, 1998: 136)

Según Oakeshott, la política de la fe tiene como reverso contraproducente el control total y minucioso de las actividades humanas en nombre de algún ideal perfeccionista; termina aboliendo la política; instiga el fervor y la devoción por una meta utópica; induce la renuncia y privación al servicio de la ardua empresa, así como somete a los ciudadanos a la seguridad aportada por una vigilancia panóptica y un poder absoluto (Oakeshott, 1998: 128-143). En la alegoría de "La Torre de Babel", los ciudadanos parecen escenificar la némesis de la fe, esto es, las consecuencias fatales de la obsesión por consumar una abundancia infinita paradisiaca, o bien el destino autodestructivo de una forma de vida consagrada a la satisfacción absoluta y definitiva:

Así, se disponen a comenzar la tarea como un pueblo con numerosos deseos y necesidades que cree que el paraíso es un lugar donde se pueden satisfacer de inmediato. Sin embargo, la dedicación a la tarea luego los convierte en un pueblo con una sola necesidad: llegar al cielo. (Oakeshott, 2013a: 176) 
Asimismo, la segunda versión de "La Torre de Babel", Oakeshott parece ilustrar algunas de las características de la moral colectivista que había retratado en las Harvard Lectures de 1958, publicadas póstumamente en 1993 bajo el título Moral y politica en la Europa moderna. En sus conferencias de Harvard, el pensador británico describió diferentes modalidades de autocomprensión de la vida moral en la modernidad, que habían surgido de la erosión de la moral tradicional de los vínculos comunales y del desgaste de los usos locales consuetudinarios de la Europa premoderna. Según Oakeshott, en el mundo moderno se abrió camino una nueva disposición moral individualista, caracterizada por la valoración de la disposición a elegir por uno mismo, así como por la aprobación y promoción de la conducta autodeterminada (Oakeshott, 2008: 60-65). Sin embargo, la moral moderna no solo consiste en cierto desplazamiento de la moral de los vínculos comunales por la moral del individuo, ya que también se dio una disposición moral anti-individualista como reacción por parte de quienes no tenían las capacidades para autodeterminarse y responsabilizarse de su propia suerte. Así surgió una moral colectivista centrada en la nivelación de las capacidades individuales, en la igualdad y en la solidaridad, que promovía el bien público o el bien común como condición sustantiva universal por encima de los proyectos individuales, y consagraba la colectividad como valor exclusivo y uniforme (Oakeshott, 2008: 69).

La alegoría de "La Torre de Babel" también pone en escena la subordinación de los individuos a un propósito social y su nivelación al encontrarse privados por igual de cuanto desean. En el relato de Oakeshott, el proyecto de Babel involucra un compromiso explícito con una moral colectivista, como lo entienden las autoridades de la ciudad:

[...] cuando se están llevando a cabo grandes obras para promover la prosperidad de todos, los intereses privados deben someterse al bien público. Y tal confirmación de la soberanía de la utilitas publica pone fin a la historia civil de Babel. (Oakeshott, 2013a: 172)

Por supuesto, la segunda versión de "La Torre de Babel" recoge los dilemas conceptuales presentes en los planteamientos teóricos de Oakeshott entre los años setenta y ochenta, tal como aparecen formulados en On Human Conduct (publicado en 1975) o en el ensayo "El concepto de rule of law" (incluido en el libro Sobre la bistoria y otros ensayos de 1985). De hecho, algunos aspectos alegóricamente retratados en este relato de la Torre de Babel se pueden rastrear hasta las lecciones impartidas por Oakeshott en la London School of Economics a finales de los sesenta. En las lectures sobre el carácter del Estado europeo moderno, el pensador britá- 
nico oponía como tipos ideales las interpretaciones telocrática y nomocrática de la actividad de gobernar. En el planteamiento telocrático, la actividad del gobierno se concebiría como el diseño subordinado a un único fin o propósito predeterminado, de manera que gobernar implicaría organizar a los súbditos, administrar los recursos territoriales y humanos, así como custodiar la solidaridad de la comunidad para la consecución de ese objetivo comprehensivo o condición sustantiva de todos los asuntos humanos (la salvación, el bienestar, la productividad o la seguridad) (Oakeshott, 2013b: 145-156). En la interpretación nomocrática, el gobierno se comprendería como imperio de la ley y provisión de reglas formales de conducta para los ciudadanos; se trataría de instituir un sistema de normas legales vigentes, que garanticen derechos y estipulen deberes y, por tanto, de regular las condiciones en que las personas puedan perseguir sus fines sustantivos, sin que se imponga una meta única a los súbditos (Oakeshott, 2013b: 157-164).

Esta distinción entre las interpretaciones nomocrática y telocrática también aparece en On Human Conduct (concretamente, en el ensayo final "On the Character of a Modern European State"), pero aparece vinculada a una reconstrucción previa de las modalidades de comprensión de la actividad humana y de la asociación inter homines, en los ensayos iniciales del libro. El primer ensayo, titulado "On the Theoretical Understanding of Human Conduct" no solo formulaba el presupuesto teórico de que la actividad humana inteligente y libre consiste en prácticas, o sea, conjuntos de condiciones procedimentales y convenciones normativas que suministran idiomas vernáculos de expresión, autodescubrimiento, motivación e interacción; además, establecía una diferencia conceptual entre las prácticas instrumentales y la práctica moral. Para Oakeshott, la actividad instrumental y las formas de cálculo prudencial persiguen satisfacciones deseadas y sostienen transacciones funcionales al logro de algún propósito sustantivo. Por otro lado, la práctica moral se perfila como un arte genérico de toda actividad humana: no se confunde con algún arte prudencial relativo al éxito de las empresas humanas ni resulta instrumental a algún propósito sustantivo o satisfacción buscada, ya que solo especifica condiciones reconocibles y consideraciones formales a suscribir para autointerpretarnos y escoger libremente, como si se tratase de un idioma de autodescubrimiento, trato y conversación, que no instruye actuaciones o enunciados predeterminados (Oakeshott, 2003: 60-62).

En el segundo ensayo de On Human Conduct ("On the Civil Condition”), Oakeshott formula otra distinción teórica relacionada con la diferenciación entre actividad instrumental y práctica moral, y caracteriza dos tipos ideales de asociación: la asociación de empresa (enterprise association) y la asociación civil. A diferencia de la relación transaccional en que dos 
agentes persiguen satisfacer sus intereses y satisfacciones sustantivas a través de la respuesta recíproca, la asociación de empresa constituye una modalidad de relación sustentada en la búsqueda conjunta de alguna satisfacción común o propósito colectivo sustantivo (prosperidad o seguridad, por ejemplo), así como en la administración de la búsqueda y en el compromiso gerencial como participante de una fe común, una empresa productiva, una corporación o una comunidad (Oakeshott, 2003: 114117). En el ensayo "El concepto de rule of law", incluido en Sobre la historia y otros ensayos (el mismo libro que contiene la segunda alegoría de "La Torre de Babel"), Oakeshott retoma esta distinción entre la asociación moral, esto es, la modalidad de relación humana en términos del reconocimiento mutuo de condiciones normativas o reglas autorizadas de comportamiento, $y$, por otro lado, las asociaciones transaccionales y la asociación de empresa, caracterizada así:

En este caso, la asociación es el ensamblaje de un agregado de poder para componer una identidad corporativa o asociativa destinada a procurar una satisfacción deseada. Esta se constituye con la elección y reconocimiento de un objetivo en común al que cada socio se compromete a dedicar un quantum de su propio poder, es decir, de su tiempo, su energía, sus recursos, sus aptitudes, etc. (Oakeshott, 2013a: 123)

Sin embargo, existe un modo de relación categorialmente distinto, la asociación civil, que consiste en la relación moral en términos del reconocimiento de las consideraciones formales y condiciones normativas de una práctica moral o de un lenguaje de comprensión y trato entre ciudadanos, tal como se articulan en las reglas auténticas de un sistema legal autorizado. Como algo distinto de una empresa, una economía o una organización pedagógica o terapéutica, esta modalidad de asociación humana no promueve algún propósito común sustantivo o necesidad colectiva, sino que hace posible la relación constitutiva y no instrumental entre ciudadanos libres e iguales; así, la asociación civil sustenta la idea de la cosa pública (la respublica) como una práctica moral de civilidad basada en el reconocimiento de la autoridad de las condiciones normativas bajo las cuales los agentes pueden escoger libremente y autodescubrirse (Oakeshott, 2003: 121-122 y 182-184).

A partir de la diferenciación categorial entre los tipos ideales de la asociación de empresa y la asociación civil, Oakeshott introduce en el ensayo final de On Human Conduct ("On the Character of a Modern European State") la distinción entre interpretaciones telocráticas y nomocráticas del gobierno; pero la dicotomía entre telocracia y nomocracia se basa, a su vez, en la distinción que el pensador británico plantea entre 
dos modos de comprender la modalidad de asociación y el carácter del Estado europeo moderno, a saber: la idea de societas y el vocabulario de la universitas. Por una parte, el vocabulario de la societas remite a una autocomprensión de la asociación humana como asociación civil, esto es, como la relación no instrumental entre agentes libres que se vinculan formalmente en términos de la lealtad mutua y del reconocimiento de la autoridad de las condiciones normativas estipuladas en un lenguaje moral y un sistema legal. En suma, cuando el Estado se comprende como societas, se concibe como una asociación civil cuyo gobierno es nomocrático (Oakeshott, 2003: 201-203). Por otra parte, el vocabulario de la universitas designa un modo de autointerpretación de la asociación humana como si esta constituyera una persona colectiva o corporación de personas que persiguen instrumentalmente un propósito común o empresa conjunta para la satisfacción de alguna necesidad colectiva concreta; en ese sentido, el Estado que se concibe como universitas ejerce el gobierno de modo telocrático, es decir, como gestión y administración de una empresa propositiva y finalista (Oakeshott, 2003: 203-206).

En la perspectiva de Oakeshott, aunque las analogías de la societas y la universitas, así como las interpretaciones nomocráticas y telocráticas de la actividad de gobernar, hayan coexistido en el ambivalente vocabulario político occidental y en la autocomprensión polarizada del Estado europeo moderno, en el curso de la Modernidad ha ganado terreno la concepción del Estado como corporación empresarial que hay que administrar telocráticamente como si se tratase de una comunidad necesitada o civitas cupiditatis. Entre las exploraciones modernas de la autocomprensión del Estado como universitas, Oakeshott incluye realizaciones históricas y experimentos políticos contemporáneos que encarnan las distintas versiones de gobierno telocrático (religiosa y redentora, ilustrada, productivista, distributiva o terapéutica); por ejemplo, menciona los estados confesionales o repúblicas cristianas postridentinos, el despotismo ilustrado, los experimentos del Estado industrial, empresarial, colectivista o asistencial (Oakeshott, 2003: 279-312).

Si leemos la segunda alegoría de "La Torre de Babel" con estos dilemas teóricos en mente (la distinción entre actividad instrumental y práctica moral, la oposición entre asociación de empresa y asociación civil, o bien la distinción entre la universitas administrada telocráticamente y la societas gobernada nomocráticamente en el marco de la rule of law), parece evidente que Babel pone de manifiesto la némesis irónica de una forma de vida humana concebida exclusivamente en torno a la actividad instrumental y transaccional, que se termina transformando en una asociación empresarial o corporación administrada telocráticamante. Oakeshott anticipa esta interpretación de la alegoría, al comienzo de su propia 
versión del relato, como retrato de una condición humana caída que parece escenificar los males de la pleonexia y del individualismo posesivo:

[...] los seres humanos se llenaron de deseos y necesidades ilimitados y comenzaron a sentir unas ansias salvajes de satisfacerlos. Indiferentes a su belleza, desdeñosos frente a sus dones y convencidos de su hostilidad, sembraron la devastación en el mundo, buscando solamente gratificar sus deseos perversos e insaciables. Sus relaciones con los otros seres humanos siguieron el mismo modelo, animadas por la codicia, la envidia, el miedo y la violencia. (Oakeshott, 2013a: 160)

Por lo demás, cuando la narración detalla la suerte de las tribus de Sem, Jafet y Cam (ancestro del megalómano Nimrod, el constructor de la Torre de Babel), queda claro que hay otras opciones distintas de la relación instrumental, el deseo ilimitado, la ambición impía y los proyectos titánicos autodestructivos; así lo ilustra la condición de la estirpe europea de Jafet, que habría apostado por mantener un vínculo social basado en la asociación civil, como la concibieron Hobbes o Hegel (Oakeshott, 2013a: 161). No obstante, la alegoría de Babel relata otro curso de la condición humana: una ciudad terrenal que se sostiene en el tráfico de las compras y en el consumo, en la exacerbación del deseo inagotable y la inducción de necesidades ilimitadas, en el entretenimiento inconstante y la variabilidad de la moda, así como en una libertad egoísta y autocomplaciente, sin virtud ni disciplina. Como forma de vida que solo se sostiene en actividades exclusivamente instrumentales y relaciones transaccionales al servicio de la satisfacción de necesidades siempre insatisfechas, Babel se ve expuesta a la frustración inevitable de un deseo desmedido:

En síntesis, Babel es una civitas cupiditatis, y sus habitantes, aunque no gozan de una riqueza pasmosa, son un pueblo dedicado a la riqueza. Desde cierto punto de vista, este relato de Babel es el relato de una némesis de la codicia. (Oakeshott, 2013a: 168)

Esta segunda versión del relato de la construcción y derrumbe de la Torre de Babel ilustra el devenir dialéctico de la codicia en la vida social: su transformación en resentimiento insatisfecho; la concreción de la ambición ilimitada en proyectos titánicos para lograr una profusión sin límites; la anteposición del ideal y el propósito colectivo a los derechos personales; la movilización total y administración plenipotenciaria de todos los recursos; la fusión comunitaria; la propaganda ideológica, el encuadramiento educativo funcional y el condicionamiento psicológico; el 
empobrecimiento del lenguaje, la actividad y la imaginación humanas, subordinados al logro de la empresa colectiva y colonizados por las consignas ideológicas, por la información acrítica y por los experimentos tecnológicos; la ansiedad y estrés emocional en torno a la empresa titánica y su incumplimiento, así como el desencantamiento resentido y la desconfianza generalizada (Oakeshott, 2013a: 170-179). En fin, la alegoría de esta versión de "La Torre de Babel" se asemeja suficientemente a nuestra sociedad mercantilizada y de consumo, así como parece anticipar los riesgos de inversión de la codicia en formas de vida totalitarias.

\section{CONCLUSIÓN: AMBIVALENCIA Y MODERNIDAD DE LA BABEL DE OAKESHOTT}

Como ya hemos argumentado, las interpretaciones contemporáneas de la alegoría de Babel podrían situarse básicamente en algún punto de la siguiente encrucijada: por un lado, encontramos exégesis teológicopolíticas (como las de Niebuhr o Hildebrand) que emplean la imagen de la construcción colosal para denunciar los riesgos del titanismo racionalista moderno y las falsas ilusiones de la ideología contemporánea; por otro lado, hallamos metainterpretaciones poético-deconstructivas de la situación postbabélica, alusivas a la inevitabilidad de la traducción y la exégesis bajo la condición de confusión de las lenguas y diseminación de los registros. ¿Dónde se sitúan los dos ensayos de Oakeshott titulados indistintamente "La Torre de Babel"? Al considerar - como hemos intentado en este trabajo- no solo la función alegórica de Babel en cada ensayo, sino también los horizontes de significado aportados por el campo discursivo en el cual se inscribe y resignifica cada texto, se aprecia que las dos torres no son gemelas ni replican su mensaje.

En la primera versión de "La Torre de Babel", predomina figurativamente el cuestionamiento del racionalismo moral y los riesgos del perfeccionismo titánico; sin embargo, opera como trasfondo algo más que el tono anti-racionalista de los escritos contenidos en El racionalismo en la politica y otros ensayos, ya que también resulta audible la invocación de la multiplicidad de las voces conversacionales de la humanidad, que Oakeshott reivindica en textos como "La voz de la poesía en la conversación de la humanidad". Así pues, el primer texto de "La torre de Babel" emplea el motivo de Babel como emblema o símbolo discreto del perfeccionismo racionalista, aunque en contigüidad con ese motivo se invoca la diversidad de modos de la imaginación humana y la creatividad de la voz poética en una condición postbabélica de pluralidad de registros.

La segunda versión de "La Torre de Babel" despliega una alegoría comprehensiva y pone figurativamente en escena diferentes motivos de 
las inquietudes intelectuales de Oakeshott en la Postguerra, tal como se reconocen explícitamente en textos próximos a esta versión y que le sirven de trasfondo discursivo (como On buman conduct, o bien "El concepto de rule of law"). Además de la crítica del racionalismo, reconocemos la ponderación de los riesgos de la política de la perfección, del colectivismo y de la autocomprensión del Estado europeo moderno en términos instrumentales y transaccionales, como corporación empresarial que habría de ser administrada telocráticamente.

En suma, el motivo de Babel exhibe la tensión inevitable entre el emblema o alegoría de la construcción de la torre y el escenario supuestamente ruinoso de la confusión de los registros; apela tanto a un reconocimiento de nuestra condición postbabélica y una invocación de las distintas voces conversacionales de la humanidad cuanto al cuestionamiento de la ambición titánica del racionalismo moderno y de la planificación ideológica potencialmente totalitaria. Por eso, en los ensayos de Oakeshott, Babel escenifica la propia encrucijada de las interpretaciones de Babel: recorre la vía interpretativa teológico-política que cuestiona el titánico racionalismo moderno, pero no incurre en la nostalgia de la comunión salvífica o en la idealización de la comunidad premoderna; explora el camino exegético poético-deconstructivo, que asume la dispersión contingente de los registros, pero no celebra la dispersión indiferente de los significantes ni el carnaval posmoderno.

Los estudiosos de la obra de Oakeshott no parecen atender a esta ambigüedad de la alegoría de Babel, y suelen concentrarse en alguna de las posibles significaciones de la alegoría: el sentido moral, la dimensión religiosa o el mensaje político. Aunque la primera versión introduzca la discusión filosófica de dos concepciones de la moralidad, mientras que la segunda presenta una nueva alegoría moderna de Babel, se podría reconocer en ambos textos un común cuestionamiento de los atajos morales racionalistas, del seguimiento servil de reglas o la sujeción bajo proyectos perfeccionistas, así como una reivindicación de cierta moralidad habitual, afectiva y creativa, incluso poética y estética. De ese modo, una lectura ética y estética de las dos versiones de "La Torre de Babel", nos invitaría a explorar cierta moralidad de la actividad auto-consumada y sin propósito ulterior, esto es, sub specie aeternitatis (Corey, 2006: 152-154). En todo caso, no parece razonable suponer una moraleja ética para la alegoría de Babel en el pensador que precisamente había considerado pseudofilosófica y abstractamente indeterminada cualquier pretensión ética de definir los conceptos morales, valores o ideales últimos, al margen de la experiencia práctica y de la totalidad concreta de la experiencia humana (Oakeshott, 1966: 332-346). 
En una perspectiva teológica, cabría pensar que ambos ensayos sobre "La Torre de Babel" simbolizan el despropósito inherente a una desmedida autoconciencia reflexiva, al seguimiento deliberado de reglas, planes o propósitos perfeccionistas, pues tiene como reverso la servidumbre al ideal y el vaciado de sentido de la vida humana cotidiana (Botwinick, 2011: 29). Por eso, el cuestionamiento del racionalismo que Oakeshott realiza a través de la alegoría de Babel encerraría una crítica al gnosticismo (es decir, a la creencia en una emancipación salvífica mediante la iniciación en un conocimiento secreto cuasi-divino de la verdad espiritual y del diseño cósmico): el gnosticismo sería un racionalismo religioso, así como el racionalismo constituiría un gnosticismo político (Botwinick, 2011: 35). Como contrapartida, los dos ensayos pondrían de manifiesto cierta teología negativa que asume nuestra finitud y, políticamente, se traduce en la apuesta agnóstica por el limitado gobierno nomocrático y la asociación civil contingente, en lugar de la omnicompetente administración telocrática y la consagración de un propósito sustantivo único (Botwinick, 2011: 42-48). Ciertamente, la segunda versión de "La Torre de Babel" incorpora una caricatura de la creencia religiosa transaccional en un Dios proveedor o un déspota divino benevolente, califica como recurso gnóstico a la búsqueda de soluciones tecnológicas, así como ilustra las desafortunadas racionalizaciones de una Nueva Teología que hace doctrina de la miseria divina y del plan de expropiación del paraíso. Sin embargo, no parece imponerse una exégesis teológica de la alegoría o algún tipo de teología política, ya que Oakeshott parece concebir una forma de vida sustentada en la vinculación civil, como la del Estado europeo moderno, que no constituye una comunidad salvífica ni consagra un solo propósito sustantivo (Oakeshott, 2013a: 161).

En una exégesis política, se puede reconocer en la Babel de Oakeshott - particularmente en la segunda versión - una alegoría de la ruinosa búsqueda de la perfección que ha caracterizado a empresas políticas telocráticas como las utopías totalitarias, en desmedro de una comprensión nomocrática del Estado democrático de derecho y del constitucionalismo moderno (Cheung, 2015: 100). En concreto, el segundo ensayo de "La Torre de Babel" escenificaría alegórica y poéticamente la respuesta de Oakeshott al totalitarismo, tal como lo ilustran la ideología del comunismo o del nazismo; pero, además, introduce una marcada sospecha hacia una versión contemporánea de Babel, ilustrada por la sociedad de la afluencia, del consumo y del entretenimiento, que se entrega al deseo exacerbado como civitas cupiditatis (Cheung, 2015: 109). Así pues, en la alegoría actualizada de Babel que Oakeshott propone, cabría reconocer una consideración de las patologías asociadas a la colonización mercantil del mundo de vida y a la administración telocrática integral de todos los 
recursos sociales, como si se tratase de una corporación empresarial volcada al consumismo y al populismo (Cheung, 2015: 112).

Desde nuestra perspectiva, la exégesis de las dos versiones "La Torre de Babel" no puede reducirse a un motivo exclusivo y monológico, sin arriesgar la ambivalencia y productividad poética de las alegorías de Babel en Oakeshott. Para el pensador británico, Babel es al mismo tiempo una figuración de la desmesura del perfeccionismo racionalista y un reconocimiento de fondo de la ineludible fragmentación de las voces que concurren en la conversación humana. En ese sentido, Babel encierra, quizá, cierta estética de la vida autoconsumada, o bien cierta asunción agnóstica de la finitud humana; pero, sobre todo, la alegoría recoge la deriva intelectual de Oakeshott, así como los dilemas que se le plantearon, en su intento de concebir la civilidad y la respublica como una asociación eminentemente normativa y moral.

Finalmente, en lo más profundo de la alegoría propuesta en las dos versiones de "La Torre de Babel", se reconoce un sutil trasfondo mitopoético, concordante con la visión que Oakeshott tenía de la escritura filosófica. En una conferencia radial de 1947 titulada "Leviathan: a Myth", Oakeshott había reivindicado la dimensión imaginativa y poética de la literatura filosófica, al comentar los méritos del libro de Hobbes (Oakeshott, 1975: 159-163). Para Oakeshott, la civilización humana comparte siempre un sueño colectivo fundacional, que se concreta en un mito originario y en cierta interpretación imaginativa de los misterios de la vida humana, sin pretender entregar una solución unívoca. En ese sentido, la gran literatura y el arte poético constituirían una rememoración y recreación sofisticada de la capacidad imaginativa de una comunidad, de manera que el poeta sueña más profundamente el sueño compartido y expande nuestra capacidad de soñar, al esbozar nuevas posibilidades infinitas. En el caso de la literatura filosófica más iluminadora, el incremento poético de nuestra capacidad imaginativa da paso a una mayor conciencia de las opciones encerradas en nuestros mitos, mediante la articulación de su inteligibilidad (Oakeshott, 1975: 159-160). Del mismo modo que saludaba el mito hobbesiano del Leviathan como clave auténtica de su escritura filosófica (en lugar de la labor reductiva de la ciencia, que se limita a destruir el mito), cabe concluir que Oakeshott recreó un mito fundacional de la tradición cristiana, el de la Torre de Babel. Como un espejo mítico deformante, las dos versiones de esa alegoría ilustran los contrasentidos de cierta pesadilla insomne: la del racionalismo perfeccionista, el Iluminismo consumado y el utopismo moderno.

Aunque suministra cierta comprensión imaginativa de la asociación humana y de los modos de gobernarla, así como despliega narrativamente tipos ideales, concepciones malogradas y dilemas de los Estados euro- 
peos modernos, el mito de Babel no sustenta una doctrina política ni promueve un programa ideológico o alguna utopía implícita, pues en ese caso se reafirmaría el mismo racionalismo que se cuestiona alegóricamente (Boucher, 2015: 129-131). En última instancia, con la Torre de Babel, Oakeshott se limita a recrear poéticamente —en la voz más conversable de cuantas concurren en la conversación humana- una narración alegórica, cierta fábula o mito ejemplar no concluyente, acerca de los riesgos de la ambición humana ilimitada y los proyectos titánicos del racionalismo perfeccionista. De ese modo, la alegoría de Babel permite articular imaginativamente -más allá de las hormas ideológicas- cierta concepción de la civilidad como asociación humana moral, no instrumental ni gerencial. Así, el relevante legado de Oakeshott al pensamiento político contemporáneo parece inseparable de la calidad poética de su voz y del estilo imaginativo de su escritura. Eso pasa con todo clásico.

\section{REFERENCIAS}

Botwinick, A. (2011). Michael Oakeshott's Skepticism. Princeton, New Jersey: Princeton University Press.

Boucher, D. (2015). Schmitt, Oakeshott and the Hobbesian Legacy in the Crisis of our Times. En D. Dyzenhaus \& T. Poole (Eds.), Law, Liberty and State: Oakeshott, Hayek and Schmitt on the Rule of Law (pp. 123-152). Cambridge: Cambridge University Press.

Cheung, C. (2015). Rule of Law or City of Babel: Oakeshott on the TwentiethCentury State. En T. Nardin (Ed.), Michael Oakeshott's Cold War Liberalism (pp. 99-115). New York: Palgrave Macmillan.

Corey, E. C. (2006). Michael Oakeshott on Religion, Aesthetics, and Politics. Columbia, Missouri: University of Missouri Press.

Derrida, J. (1987). Torres de Babel. (C. Olmedo y P. Peñalver, trads.). ER, Revista de Filosofía, 5, 35-68.

Franco, P. (2004). Michael Oakeshott: an Introduction. London: Yale University Press.

Gay, P. (1984). La cultura de Weimar. (N. Catelli, trad.). Barcelona: Argos Vergara.

Gerencser, R. (2000). The Skeptic's Oakeshott. New York: St. Martin's Press.

Hildebrand, D. (1994). The New Tower of Babel. Manchester, New Hampshire: Sophia Institute Press.

Kracauer, S. (1985). De Caligari a Hitter. (H. Grossi, trad.). Barcelona: Paidós.

Nardin, T. (2001). The Philosophy of Michael Oakeshott. Pennsylvania: The Pennsylvania State University Press.

Niebuhr, R. (1937). Beyond Tragedy. New York: Charles Scribner's Sons.

Oakeshott, M. (1966). Experience and its Modes. Cambridge: Cambridge University Press.

Oakeshott, M. (1975). Hobbes on Civil Association. Indianapolis: Liberty Fund. 
Oakeshott, M. (1998). La política de la fe y la política del escepticismo. (E. L. Suárez, trad.). México, D. F.: Fondo de Cultura Económica.

Oakeshott, M. (2000). El racionalismo en la política y otros ensayos. (E. L. Suárez, trad.). México, D. F.: Fondo de Cultura Económica.

Oakeshott, M. (2003). On Human Conduct. Oxford: Clarendon Press.

Oakeshott, M. (2008). Moral y política en la Europa moderna. (G. López Sastre, trad.). Madrid: Síntesis.

Oakeshott, M. (2013a). Sobre la historia y otros ensayos. (M. V. Rodil, trad.). Buenos Aires: Katz.

Oakeshott, M. (2013b). Lecciones de historia del pensamiento politico (Vol. 2). (F. J. López Atanes, trad.). Madrid: Unión Editorial.

Podoksik, E. (2003). In Defence of Modernity: Vision and Philosophy in Michael Oakeshott. Exeter: Imprint Academic.

Steiner, G. (1980). Después de Babel. (A. Castañón, trad.). México, D. F.: Fondo de Cultura Económica.

Tseng, R. (2003). The Sceptical Idealist: Michael Oakeshott as a critic of the Enlightenment. Exeter: Imprint Academic. 